\title{
Influence of Melt Feeding Scheme and Casting Parameters During Direct-Chill Casting on Microstructure of an AA7050 Billet
}

\author{
L. ZHANG, D.G. ESKIN, A. MIROUX, T. SUBROTO, and L. KATGERMAN
}

Direct-chill (DC) casting billets of an AA7050 alloy produced with different melt feeding schemes and casting speeds were examined in order to reveal the effect of these factors on the evolution of microstructure. Experimental results show that grain size is strongly influenced by the casting speed. In addition, the distribution of grain sizes across the billet diameter is mostly determined by melt feeding scheme. Grains tend to coarsen towards the center of a billet cast with the semi-horizontal melt feeding, while upon vertical melt feeding the minimum grain size was observed in the center of the billet. Computer simulations were preformed to reveal sump profiles and flow patterns during casting under different melt feeding schemes and casting speeds. The results show that solidification front and velocity distribution of the melt in the liquid and slurry zones are very different under different melt feeding scheme. The final grain structure and the grain size distribution in a DC casting billet is a result of a combination of fragmentation effects in the slurry zone and the cooling rate in the solidification range.

DOI: $10.1007 / \mathrm{s} 11663-012-9711-\mathrm{x}$

(c) The Minerals, Metals \& Materials Society and ASM International 2012

\section{INTRODUCTION}

DIRECT-CHILL (DC) casting is the major technology for producing aluminum ingots and billets for further deformation processing. Usually, a fine, equiaxed grain structure and a uniform grain structure distribution across billet (ingot) are desired in aluminum casting for improving yield strength, fracture toughness, ductility, and other required properties by minimizing shrinkage, hot tearing, and segregation. ${ }^{[1,2]}$

The main casting process parameters in this technology, such as casting speed, casting temperature, melt flow feeding system, and cooling water flow conditions, are crucial to the evolution of microstructures during solidification, as well as for the formation of defects. Although invention and commercial use of DC casting could be dated back to the 1930s, and a number of studies were dedicated to the effects of process parameters on structure, relatively little is known about structure under different melt flow feeding schemes.

Generally, higher casting speed and lower casting temperature result in a finer microstructure ${ }^{[3-5]}$ while cooling water-flow rate has relatively minor effect on grain structure. ${ }^{[6,7]}$ The distribution of structure parameters in the horizontal section of a DC casting billet (along the

L. ZHANG, Ph.D. Researcher, T. SUBROTO, Ph.D. Student, and L. KATGERMAN, Professor, are with Department of Materials Science and Engineering, Delft University of Technology, Mekelweg 2, 2628 CD Delft, The Netherlands. Contact e-mail: Liang.Zhang@ tudelft.nl D.G. ESKIN, Professor, is with BCAST, Brunel University, Uxbridge, UB8 3PH, U.K. A. MIROUX, Research Fellow, is with Materials Innovation Institute, Mekelweg 2, $2628 \mathrm{CD}$ Delft, The Netherlands.

Manuscript submitted December 16, 2011.

Article published online August 21, 2012. radius or diameter) is of great importance since it determines the homogeneity of technological properties during downstream processing. The distribution of grain structure depends to a great extent on the profile of a sump (sump depth and shape), temperature distribution and the flow pattern in liquid and transition regions, which are difficult to observe directly in the real DC casting processing. ${ }^{[8]}$ The lack of these data restricts our understandings on the evolution of microstructures during DC casting.

Nowadays, various numerical and analytical simulations allow us to visualize and analyze the solidification patterns during DC casting. To fully understand what really happens during solidification and how the microstructure is formed in DC casting, both experimental and numerical analysis are essential. The numerical simulation complements the experiments study and becomes a tool of research.

Before we move on, let us specify the terms which are related to structure formation during DC casting. Solidification front is the macroscopically continuous and microscopically discontinuous front of the growing solid phase, can be also named coherency isotherm. ${ }^{[8]}$ The condition of coherency can be defined as the moment when solid grains begin to interact with each other. ${ }^{[9]}$ The region between liquidus and coherency isotherm is called the slurry zone, where solid grains float freely. The region between coherency isotherm and solidus is called the mushy zone, where the macroscopic movement of solid grains is fully restricted..$^{[8,10]}$ The slurry and mushy zones constitute a transition region. Solidification rate is the velocity of the solidification front, which is related to the casting speed and geometry of the sump during direct chill casting as:

$$
V_{\text {sol }}=V_{\text {cast }} \cos \varphi
$$


where $V_{\text {cast }}$ is the casting speed and $\varphi$ is the angle between the billet axis and the normal to the solidification front. ${ }^{[6,8]}$ Thus, the minimum solidification rate usually occurs at the position where the solidification front is the steepest. The cooling rate $V_{\text {cool }}$ in DC casting represents the rate of heat extraction when passing the solidification range, from liquidus to solidus. Generally, cooling rate is the main factor affecting microstructure during solidification. A higher cooling rate leads to a smaller dendritic arm spacing (DAS), as well as finer grains. ${ }^{[11]}$ It should be noted that the grain size depends on both nucleation and growth, only latter being explicitly dependent on the cooling rate, while the nucleation is strongly affected by other factors, such as the amount of nucleation sites, undercooling, etc. ${ }^{[12-14]}$

The effects of melt flow in the sump are relatively well studied with respect to the macrosegregation, where the macroscopic solute transport through liquid and solid phase movement acts as the main mechanism. ${ }^{[5,10,15,16]}$ The changes in the grain structure under natural or forced melt convection are far less investigated. The aim of this paper is to study the influence of melt feeding scheme and casting parameters during DC casting on microstructure of an AA7050 billet. Different melt feeding designs (melt distributor) and casting speeds were analyzed, combined with computer simulation for flow and solidification patterns, to contribute to the understanding on the evolution of microstructures during DC casting.

\section{EXPERIMENTAL PROCEDURE}

Four round AA7050 billets were cast with different casting conditions through DC casting at Tata Steel Europe, The Netherlands. The average composition of

Table I. Chemical Composition of Experimental Alloy (in Weight Percent)

\begin{tabular}{lccccc}
\hline Alloy & $\mathrm{Zn}$ & $\mathrm{Cu}$ & $\mathrm{Mg}$ & $\mathrm{Zr}$ & $\mathrm{Ti}$ \\
\hline AA7050 & 6.15 & 2.2 & 2.1 & 0.13 & 0.03 \\
\hline
\end{tabular}

these billets is shown in Table I. The chemical composition of the billets was measured using a spark spectrum analyzer (Spectro, Kleve, Germany). The melt was first degassed in the furnace at $1003 \mathrm{~K}\left(730{ }^{\circ} \mathrm{C}\right)$ and then cast with a conventional DC casting mold without hot top. The casting temperature was around $953 \mathrm{~K}\left(680^{\circ} \mathrm{C}\right)$. All billets were grain refined by the same amount of an A15Ti1B maser alloy, $2 \mathrm{~kg} /$ tonne. The diameter of cast billets was $315 \mathrm{~mm}$.

In this research, two melt feeding distributors were used. The melt was poured to the DC casting mold from the launder either through a semi-horizontal feeding distributor or a vertical feeding distributor, as shown in Figures 1(a) and (b). In the semi-horizontal feeding scheme, the melt was diverted to four branches through a cross-shaped splitter, while in vertical feeding scheme, all melt was poured directly in the center of the mold. These two kinds of feeding schemes are commonly used in experimental and industrial practice, since they are reported to have effect either on minimizing cracking or on suppressing negative central segregation through changing sump geometry and flow patterns during DC casting. ${ }^{[16,17]}$ Two casting speeds were chosen for each melt feeding scheme. The specific casting information at the steady state casting is shown in Table II. The different water flow rates that were used at different casting speeds were chosen from the safety-casting point of view and were not expected to affect the structure of the billets. ${ }^{[6,7]}$

Cast billets were sawn in a horizontal section corresponding to the steady state stage of casting. The slices were then cut into smaller samples in order to analyze the microstructure from the surface to the center of billets. The grain structures of all samples were examined in an optical microscope after being ground, polished, and electro-oxidized at $20 \mathrm{VDC}$ in a 3 pct $\mathrm{HBF}_{4}$ water solution. Grain size was measured using the linear intercept method and the statistical analysis of the results was performed.

ALSIM6 (a casting-simulation software developed by the Norwegian Institute for Energy Technology, Kjeller, Norway) was used for the computation of sump profiles and flow patterns during casting under different melt feeding schemes and casting speeds. The simulated geometry consisted of the mold, water jet, bottom block

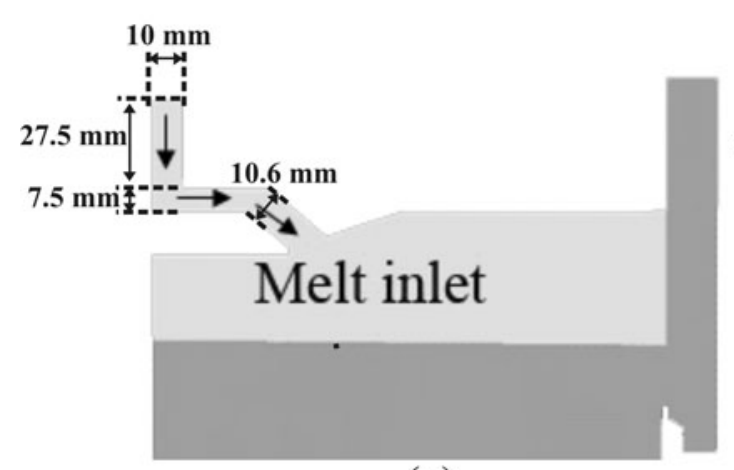

(a)

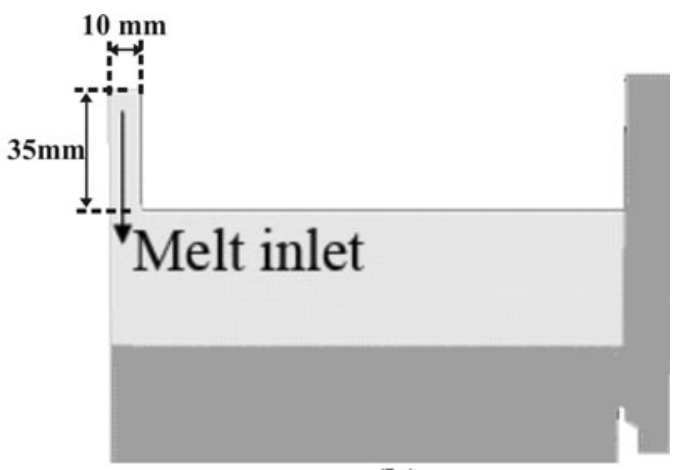

(b)

Fig. 1-Geometry of melt feeding distributors used in experiments. $(a)$ Semi-horizontal melt feeding scheme and (b) vertical melt feeding scheme. Only half of the billet is shown, centreline is on the left. 
Table II. Melt Feeding Scheme and Casting Parameters in All Billets

\begin{tabular}{llccrr}
\hline Alloy & Feeding Scheme & $\begin{array}{c}\text { Casting Temperature } \\
{\left[\mathrm{K}\left({ }^{\circ} \mathrm{C}\right)\right]}\end{array}$ & $\begin{array}{c}\text { Casting Speed } \\
(\mathrm{mm} / \mathrm{minutes})\end{array}$ & $\begin{array}{c}\text { Cooling Water Flow } \\
\text { Rate }(\mathrm{l} / \mathrm{minutes})\end{array}$ & $\begin{array}{c}\text { Casting } \\
\text { Length }(\mathrm{mm})\end{array}$ \\
\hline $\begin{array}{c}\text { AA7050 + Al5Ti1B } \\
\text { grain refiner }\end{array}$ & semi-horizontal feeding & $953(680)$ & 50 & 40 & 1255 \\
& & $953(680)$ & 90 & 40 & 1300 \\
& vertical feeding & $953(680)$ & 60 & 35 & 1130 \\
\hline
\end{tabular}

and the casting domain. In this 2D computer simulation, the heat, fluid flow, casting, and solidification modules were included in the ALSIM6 modelling set-up. The ALSIM program also calculates the heat transfer along the billet surface from the cooling water flow rate. The air gap formed between the mold and billet, which reduces the heat transfer, is also taken into account for heat transfer calculation. The calculation of a free melt surface is not included in the model, and the metal level at the top of the casting is assumed to be flat. ${ }^{[18]}$ The Navier-Stokes equations are solved in the model by considering a Darcy term. Low Rayleigh number (LRN) turbulent energy-pseudoturbulent dissipation $(\kappa-\varepsilon)$ model was chosen to solve the turbulence problem in this simulation. A more detailed description of the software setup and models involved can be found elsewhere. ${ }^{[18]}$ Thermo-physical parameters for AA7050 alloy and boundary conditions used in this simulation are also described elsewhere. ${ }^{[19,20]}$

\section{RESULTS}

\section{A. Semi-Horizontal Melt Feeding Scheme: Experimental and Simulation Results}

In the semi-horizontal feeding billet, due to the inhomogeneous melt inflow caused by four inlets, the grain structure was measured in two directions (at $45 \mathrm{deg}$ angle from each other), The distributions of grain structure were similar, which attests for the negligible effect of this feeding scheme on the symmetry of the grain structure. So in this paper, we only present the grain structure measurements from one diameter and also the modelling work treats an axisymmetric flow pattern. The examination of grain structure shows that the increase of casting speed generally results in grain refinement, as illustrated in Figure 2. The grains are coarser towards the center (Figures 3(c) and (f)), while the minimum grain size was observed near the surface (Figures 3(a) and (d)). The morphology of grains is normally dendritic, as shown in Figure 3. Similar distribution of grain structure across the billets section has been reported previously. ${ }^{[21,22]}$ It is also worth to note that the effect of casting speed on grain size is more pronounced towards to the central part of billets. This is in good agreement on our previous results. ${ }^{[5]}$

Figure 4 gives computer simulation results on sump profiles and flow patterns at two casting speeds, 50 and $90 \mathrm{~mm} /$ minutes, in the semi-horizontal feeding configuration. Through these results, the solid fraction (distribution of temperature) and velocity distribution can be

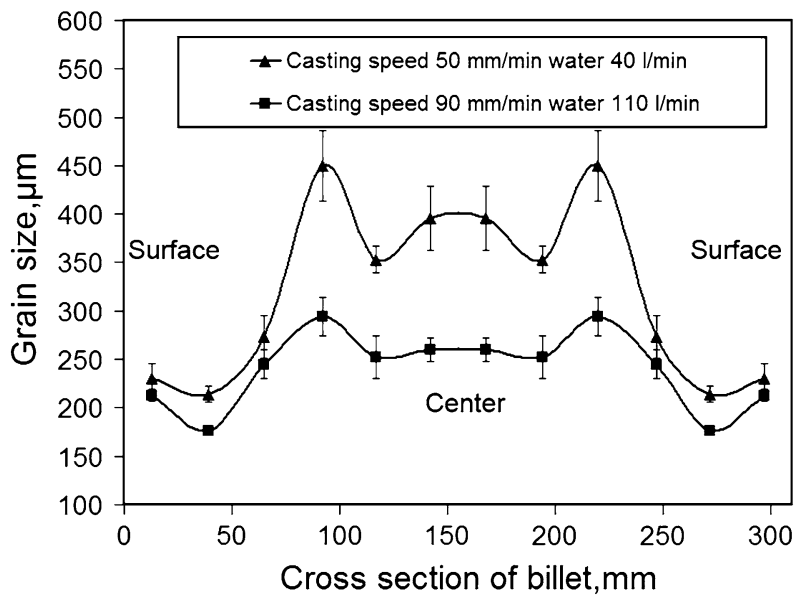

Fig. 2-Distribution of grain size in the horizontal section of a semihorizontal feeding billet at different casting speeds.

directly analyzed. With increasing casting speed, the sump depth in the center (from the melt level in the mold to the solidus) is getting deeper, from 12 to $23 \mathrm{~cm}$. Two counter-clockwise vortices are found at both casting speeds. One is centered at the quarter-radius and is most intense near the surface area, while another is closer to the center area with a moderate upstream flow in the center.

The distribution of vertical distances between liquidus $\left[901 \mathrm{~K}\left(628^{\circ} \mathrm{C}\right)\right]$ and solidus $\left[745 \mathrm{~K}\left(472{ }^{\circ} \mathrm{C}\right)\right]$ along the billet radius is shown in Figure 5(a). At both casting speeds, the distance first decreases a little near the surface and then increases towards the center. The higher casting speed results in the wider transition region towards the center and the thinner region near the surface. In the center of billet, the thicknesses of the transition region are getting closer for the two given speeds.

Taking casting speed into consideration, we can find that the larger distance between liquidus and solidus isotherms is partially compensated for by the increased casting speed. Figure 5(b) shows the estimated cooling rates along the billet radius as determined by the distance between liquidus and solidus, and the casting speed. The results demonstrate that a higher cooling rate can be obtained at a higher casting speed. At both given casting speeds, the maximum cooling rate is achieved at approximately $20 \mathrm{~mm}$ from the billet surface. The cooling rate then generally decreases from the surface towards the center, while there is a slight increase in the center. 

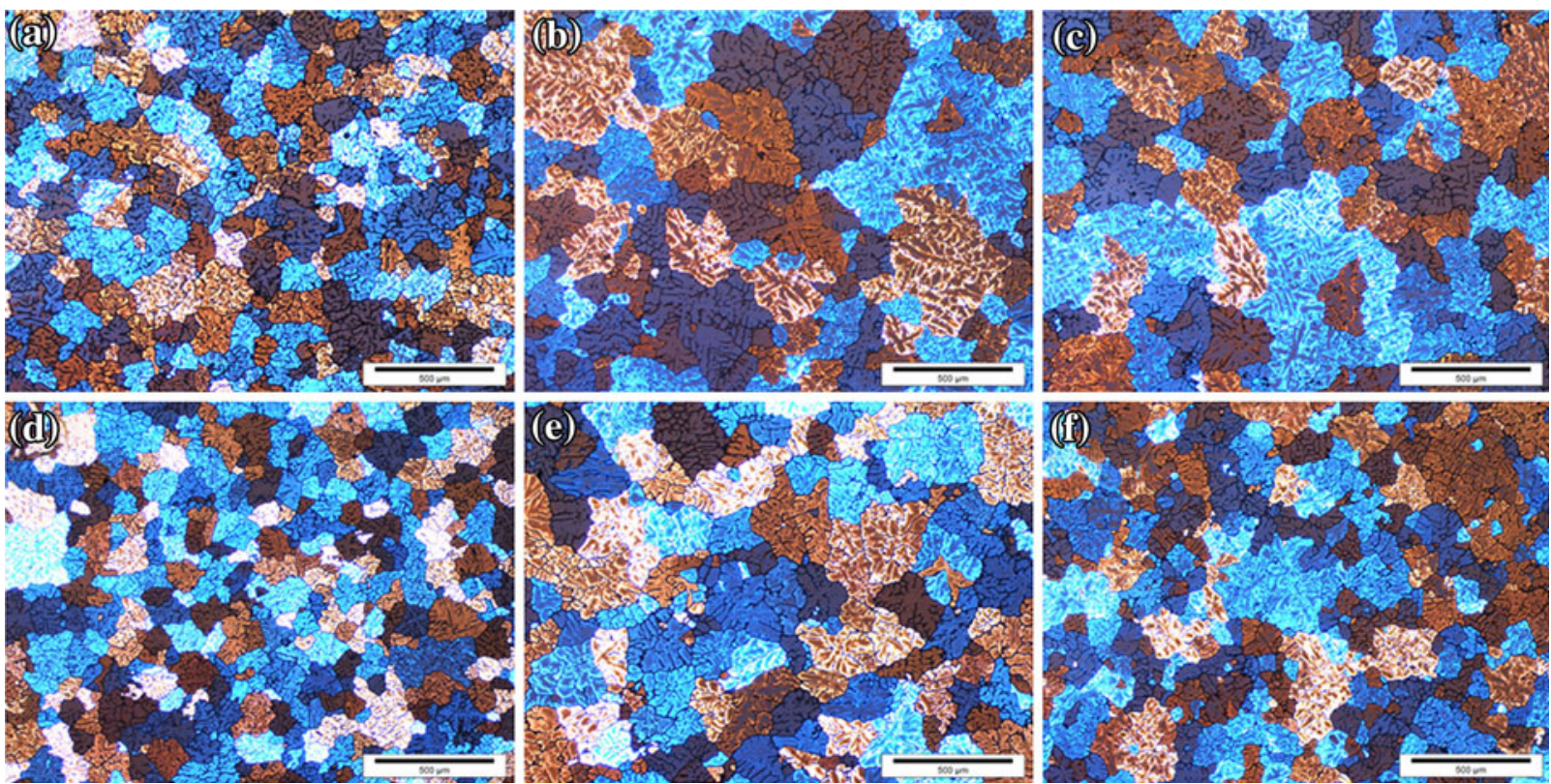

Fig. 3 - Grain structure in the horizontal section of a semi-horizontal feeding billet at different casting speeds. (a) near the surface, $40 \mathrm{~mm}$ away from the surface, $50 \mathrm{~mm} / \mathrm{min}$; $(b)$ half-radius, $90 \mathrm{~mm}$ away from the surface, $50 \mathrm{~mm} / \mathrm{min} ;(c)$ in the center, $50 \mathrm{~mm} / \mathrm{min}$; $(d)$ near the surface, $40 \mathrm{~mm}$ away from the surface, $90 \mathrm{~mm} / \mathrm{min}$; (e) half-radius, $90 \mathrm{~mm}$ away from the surface, $90 \mathrm{~mm} / \mathrm{min} ;(f)$ in the center, $90 \mathrm{~mm} / \mathrm{min}$.

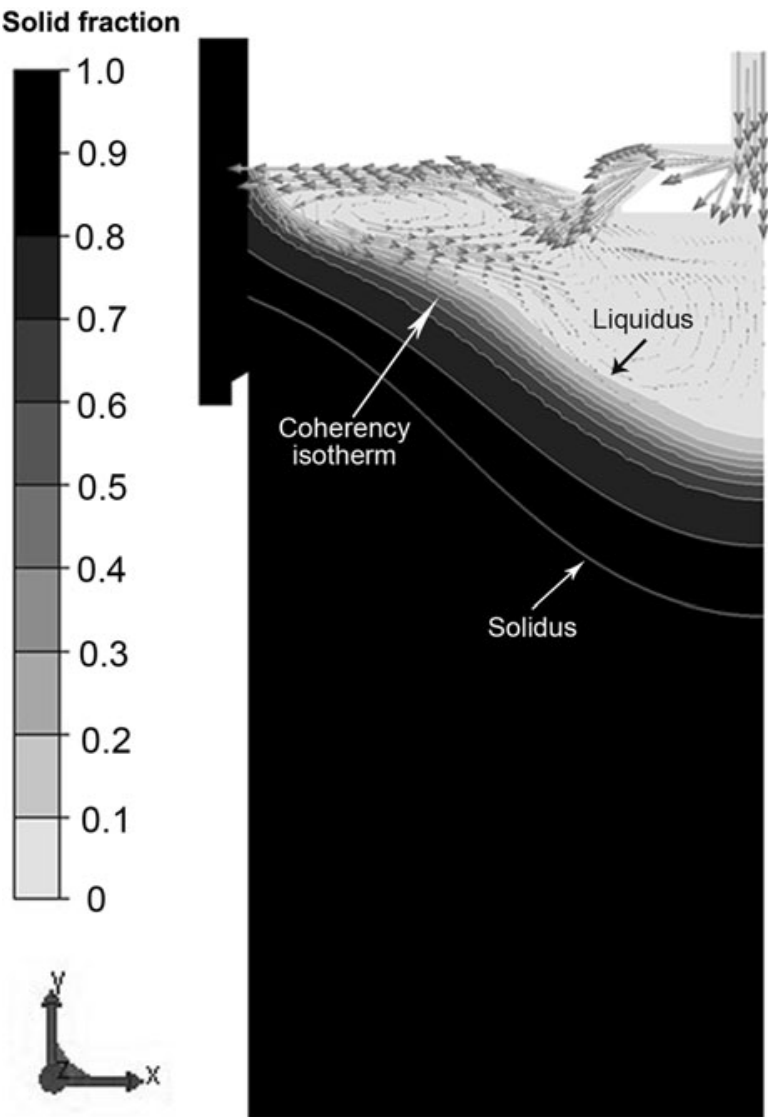

(a)

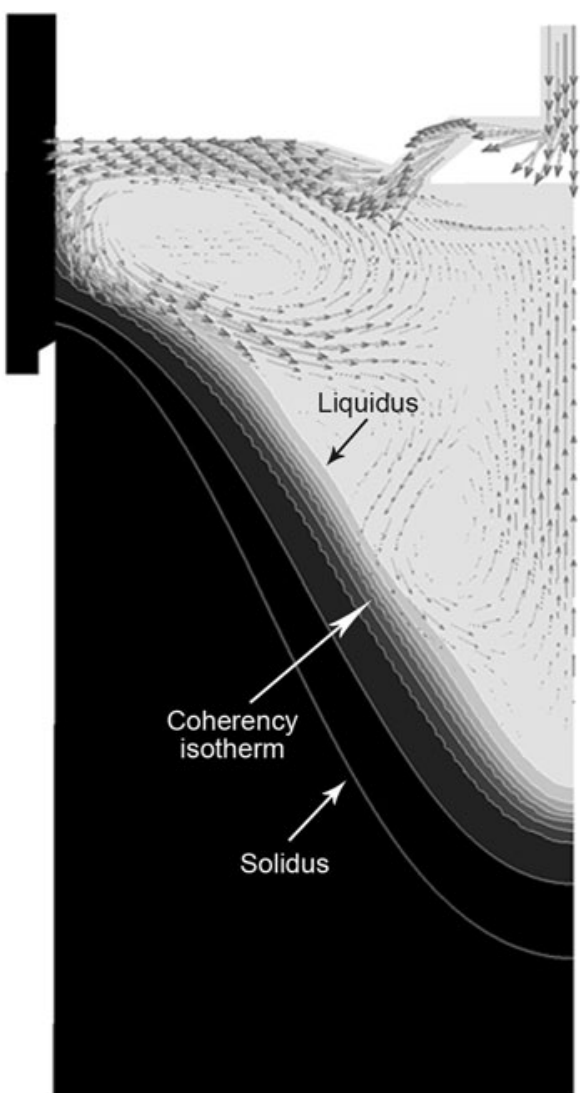

(b)

Fig. 4 - Simulated sump profiles and flow patterns in semi-horizontal feeding billets during DC casting. (a) Casting speed $50 \mathrm{~mm} / \mathrm{min}$ and (b) casting speed $90 \mathrm{~mm} / \mathrm{min}$; only half of the billet is shown, centreline is on the right. 


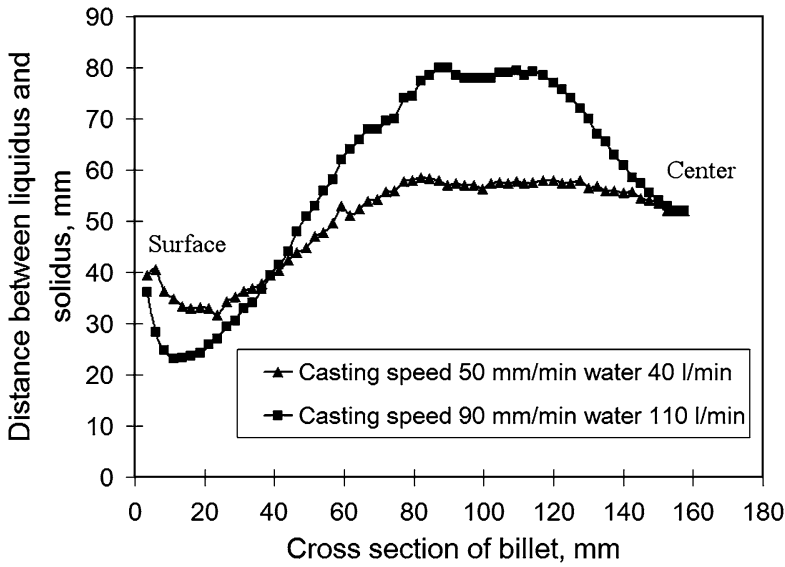

(a)

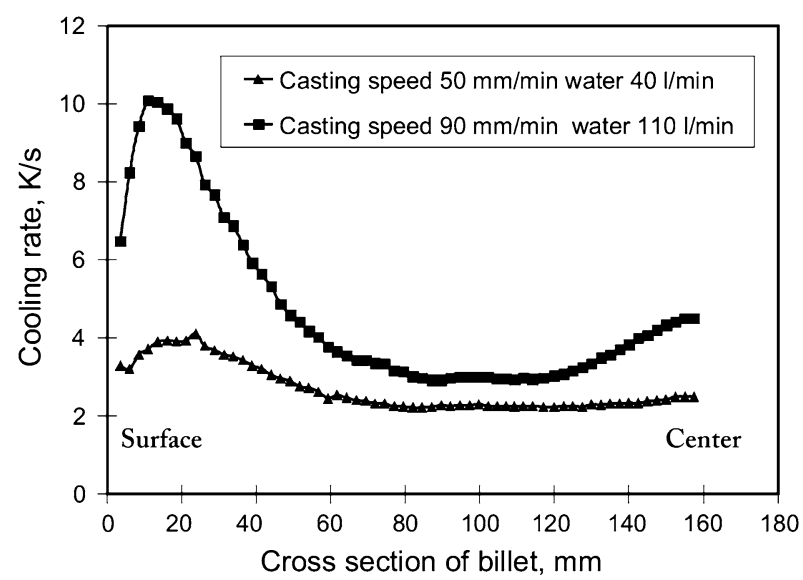

(b)

Fig. 5-Effect of casting speed on the distribution along the cross-section of semi-horizontal feeding billet of (a) distance between liquidus and solidus in the vertical direction and $(b)$ estimated cooling rate determined using distance between liquidus and solidus.

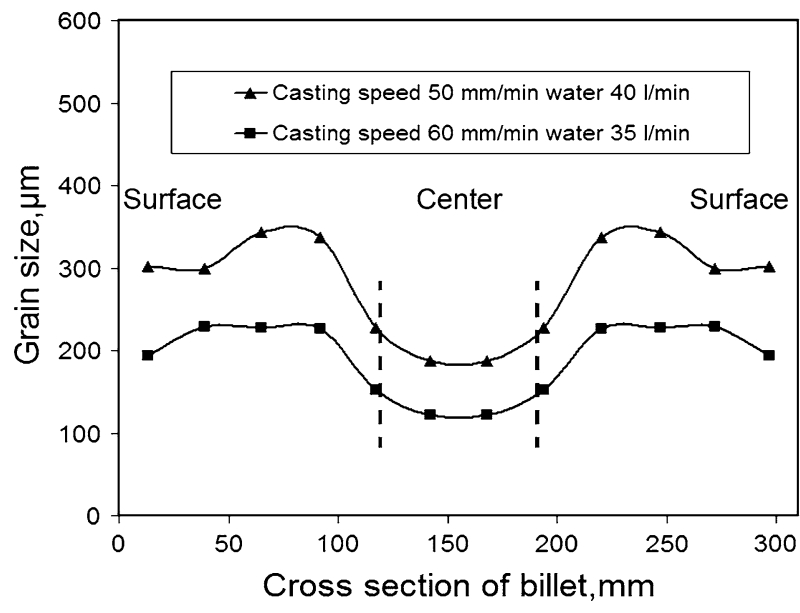

Fig. 6-Distribution of grain size in the horizontal section of a vertical feeding billet at different casting speeds. Dashed lines represent the positions where coarse grains layer is.

\section{B. Vertical Melt Flow Feeding Scheme: Experimental and Simulation Results}

In the billets cast with the vertical feeding, the distribution of grain structure is totally different as compared to that obtained upon semi-horizontal feeding, as shown in Figure 6. The minimum grain size was found in the center of billets. Although the higher casting speed also leads to a smaller grain size, the effect of casting speed on grain structure seems to be more uniform at different positions across the billets, as compared to the semi-horizontal feeding. Figure 7 illustrates how the grain structure changes along the billet radius at two casting speeds, 50 and $60 \mathrm{~mm} /$ minutes.

Another main difference from the semi-horizontal scheme is a layer of coarse grains observed at both given casting speeds as illustrated in Figure 8. The coarse grains layer is around $40 \mathrm{~mm}$ away from the center, and its thickness is approximately $1 \mathrm{~mm}$. The exact positions are shown in Figure 6 with dashed lines. It should be mentioned that the presence of these coarse grains was not taken into account during measurement of grain size in Figure 6.

Solidification patterns in the billets with vertical feeding were simulated for both casting speeds, 50 and $60 \mathrm{~mm} /$ minutes, as shown in Figure 9. The vertical melt flow inlet in the center causes a cliff-shaped sump. The slope increases dramatically at the position $40 \mathrm{~mm}$ away from the center, where the layer of coarser grains is observed. The solidification front drops almost vertically and the solidification rate at this point is virtually zero. With increased casting speed, the sump depth in the center increases (from 17 to $21 \mathrm{~cm}$ ). There are two convection flows at both casting speeds, as illustrated in Figure 9. One is near the center area, clockwise. Another is centered at half-radius and rotates in the counter-clockwise direction. Two opposite flows collide at the position 40 to $50 \mathrm{~mm}$ away from the center. The flow is more pronounced and directed downwards in the center instead of upwards in the case of semi-horizontal feeding. At the surface, on the contrary, the flow intensity is less.

Figure 10(a) gives the vertical distance between liquidus $\left[901 \mathrm{~K}\left(628^{\circ} \mathrm{C}\right)\right]$ and solidus $\left[745 \mathrm{~K}\left(472{ }^{\circ} \mathrm{C}\right)\right]$ cross section of billets. As Figure 10(a) reveals, the distance first increases towards the center and suddenly decreases rapidly near the center. The opposite trend can be observed for the estimated cooling rate, which rapidly increases near the center after a continuous decrease from the surface as illustrated in Figure 10(b).

\section{DISCUSSION}

Experimental and simulation results clearly show that casting speed and melt feeding scheme are important factors affecting cast structures in DC casting of Al-alloy billets. The observed correlation between the measured grain size distribution with the sump profile suggests that these factors mainly affect grain size through different sump profiles and flow patterns during solidification. 

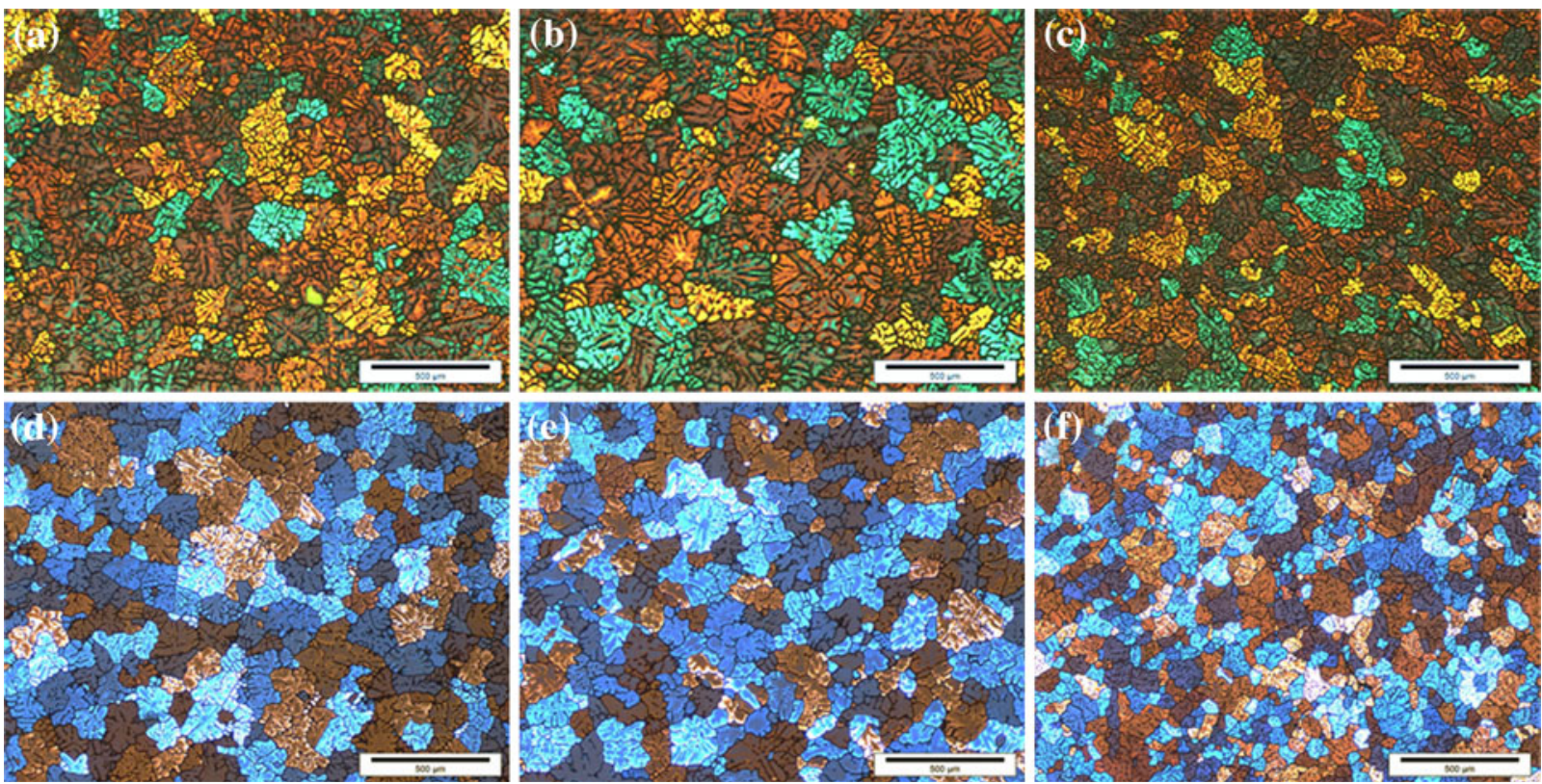

Fig. 7-Grain structure in the horizontal section of a vertical feeding billet at different casting speeds. (a) Near the surface, $40 \mathrm{~mm}$ away from the surface, $50 \mathrm{~mm} / \mathrm{min} ;(b)$ half-radius, $90 \mathrm{~mm}$ away from the surface, $50 \mathrm{~mm} / \mathrm{min} ;(c)$ in the center, $50 \mathrm{~mm} / \mathrm{min} ;(d)$ near the surface, $40 \mathrm{~mm}$ away from the surface, $60 \mathrm{~mm} / \mathrm{min}$; (e) half-radius, $90 \mathrm{~mm}$ away from the surface, $60 \mathrm{~mm} / \mathrm{min}$; $(f)$ in the center, $60 \mathrm{~mm} / \mathrm{min}$.

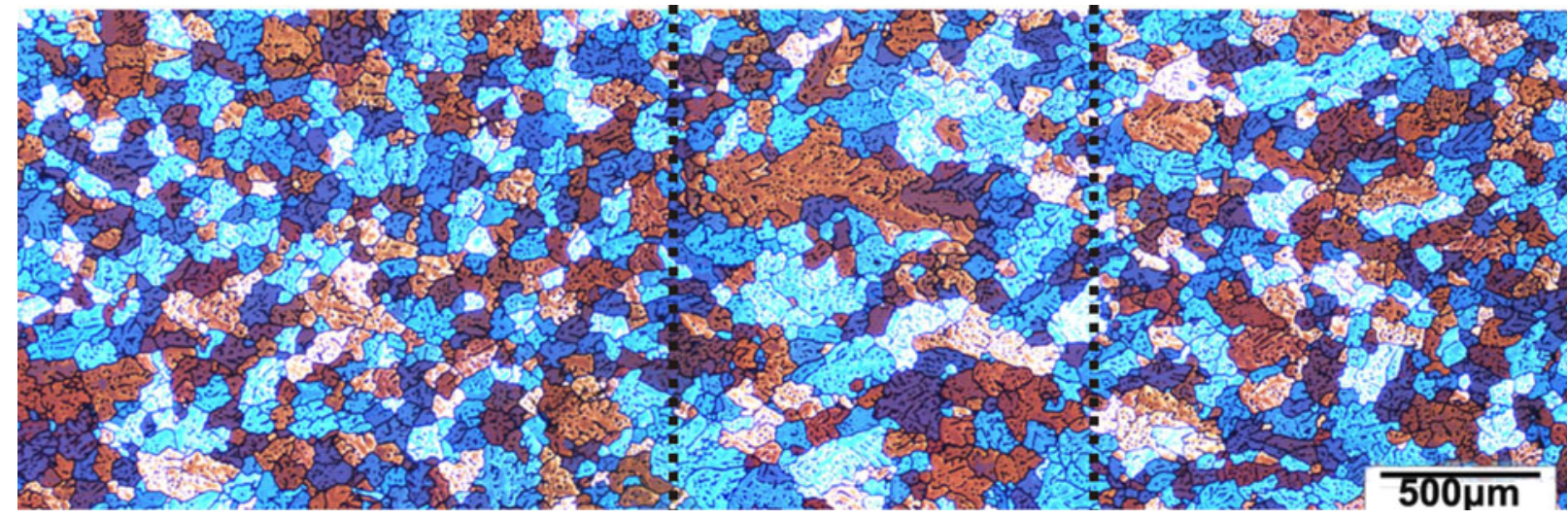

Fig. 8-A typical layer of coarse grains near the center ( $40 \mathrm{~mm}$ away from the center) found in the billet with the vertical melt feeding. Coarse grains layer is shown in dashed line area, see also Fig. 6.

The effect of casting conditions on the sump depth has been reported in many references. The main factors, such as casting speed, alloy type, casting temperature and size of casting, strongly influence the depth of sump. ${ }^{[5,8,23,24]}$ Our results confirm that the sump depth increases with increasing casting speed in both melt feeding schemes. However, at the same casting speed $50 \mathrm{~mm} /$ minutes, the vertical feeding scheme leads to a deeper sump depth $(17 \mathrm{~cm})$ as compared to semihorizontal feeding scheme $(12 \mathrm{~cm})$. Hence, the melt feeding scheme is yet another factor affecting sump depth during DC casting.

Higher casting speeds generally result in a higher cooling rate, as shown in Figures 5(b) and 10(b), and finer grain structure (Figures 2 and 6). It should be noted that during casting with semi-horizontal feeding, the casting speed was increased along with the cooling water flow rate, in order to assure safe casting (see Table II). This is why there is a significant increase in the cooling rate near the surface. The significant change in the sump shape with different melt feeding schemes (Figures 4 and 9) resulted in the different distributions of cooling rate across the section of billets produced with vertical and semi-horizontal feeding schemes, as illustrated in Figures 5(b) and 10(b). The maximum cooling rate was found near the surface in semihorizontal feeding scheme, while in vertical feeding scheme there is maximum cooling rate in the center. Taking distributions of grain size in Figures 2 and 6 into consideration, we can find there is a good correlation between simulated cooling rate and experimental grain size distribution. For instance, in the semi-horizontal feeding scheme (Figures 2 and 5(b)), the smallest grain size is near the surface where the maximum cooling rate 


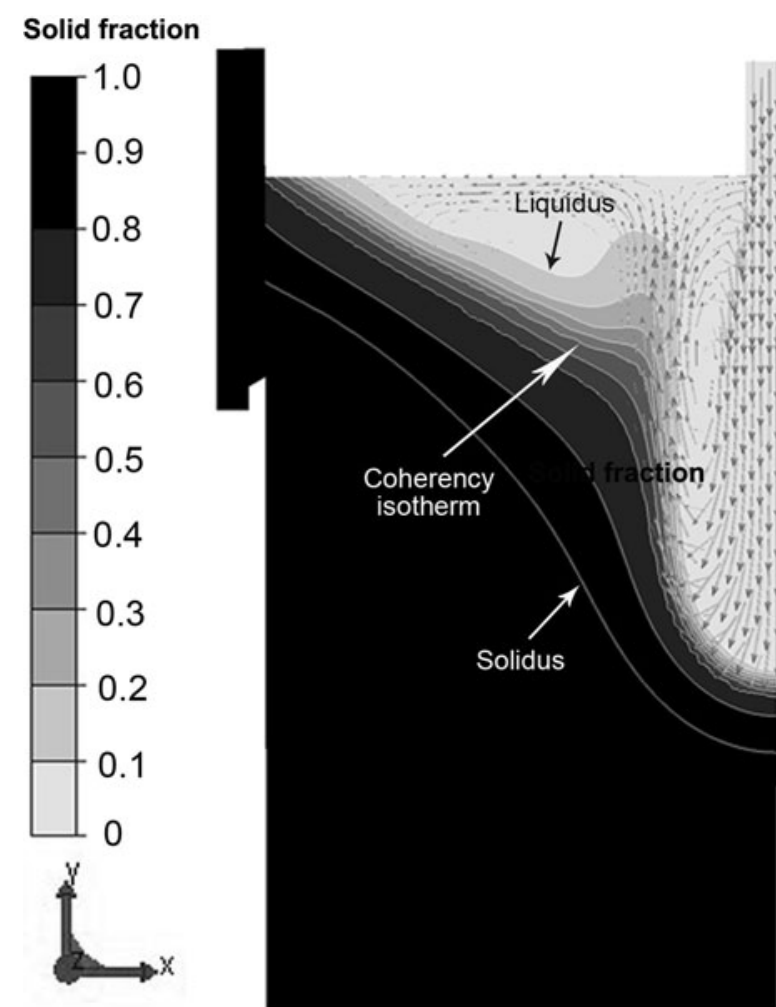

(a)

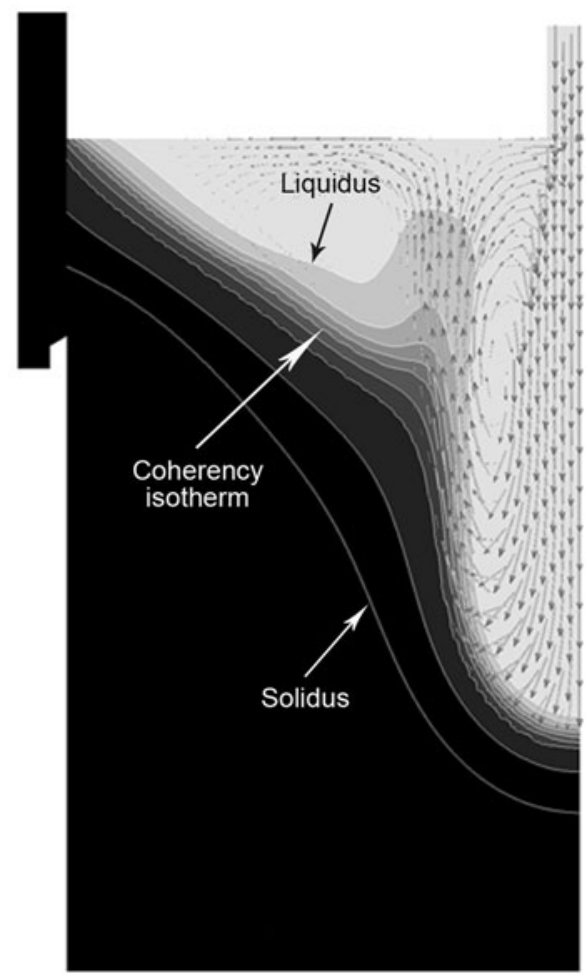

(b)

Fig. 9-Simulated sump profiles and flow patterns in vertical feeding billets during DC casting. (a) Casting speed $50 \mathrm{~mm} / \mathrm{min}$ and $(b)$ casting speed $60 \mathrm{~mm} / \mathrm{min}$. Only half of the billet is shown, centreline is on the right.

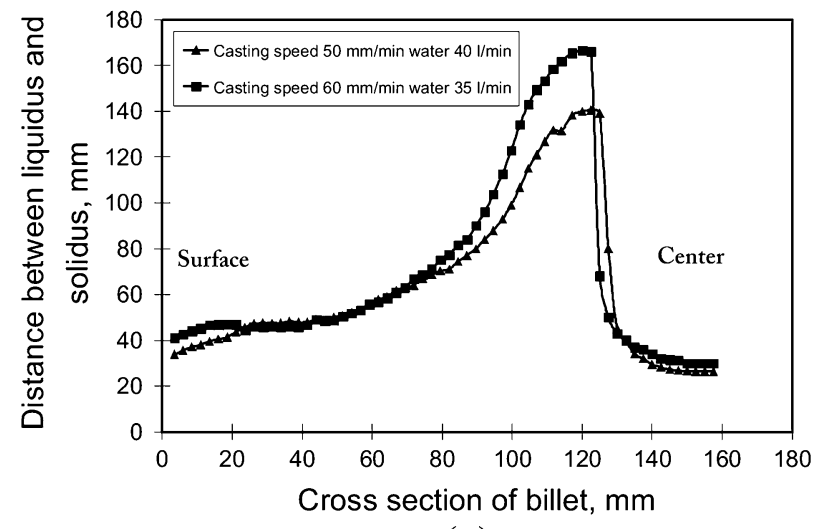

(a)

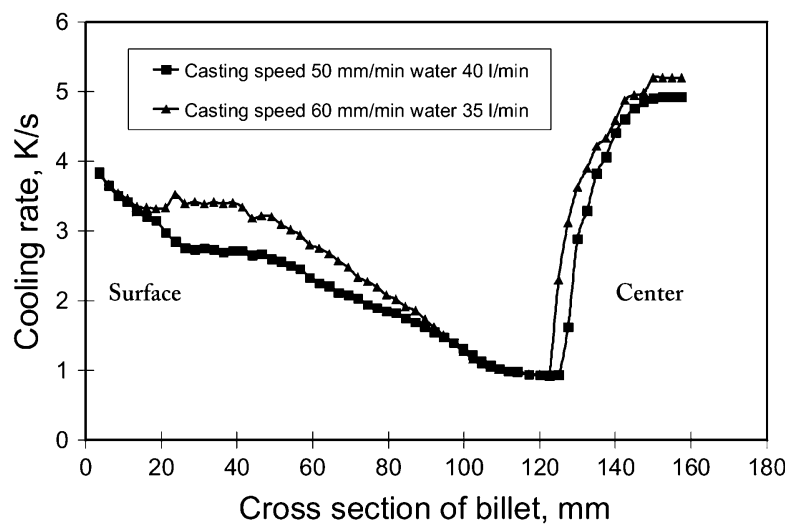

(b)

Fig. 10-Effect of casting speed on the distribution along the cross-section of the vertical feeding billet of $(a)$ distance between liquidus and solidus in the vertical direction and $(b)$ estimated cooling rate determined using distance between liquidus and solidus.

is. The grain size then increases with decreasing cooling rate until the cooling rate increases a little in the center. Similar relation can also be found in vertical feeding billets. In this case, the maximum cooling rate leads to minimum grain size in the center.

Comparing cooling rate distribution and grain size carefully, one can find however that there are some odd positions in the billet cross-section as well, which seemingly fall out of the logical picture. For instance, in vertical feeding billets, a relatively small grain size appears approximately 100 to $120 \mathrm{~mm}$ away from the surface where the cooling rate is very small. Also in semi-horizontal feeding billets, the estimated cooling rate in Figure 5(b) cannot fully represent the grain size distribution near the center (around $110 \mathrm{~mm}$ away from the surface) where relatively small grains appear as compared to neighboring area.

In the previous discussion we have not touched upon grain movement, sedimentation, and fragmentation, which can considerably affect the grain size, in addition to the cooling rate. As mentioned before, the grain size does not only depend on the cooling rate, but also 


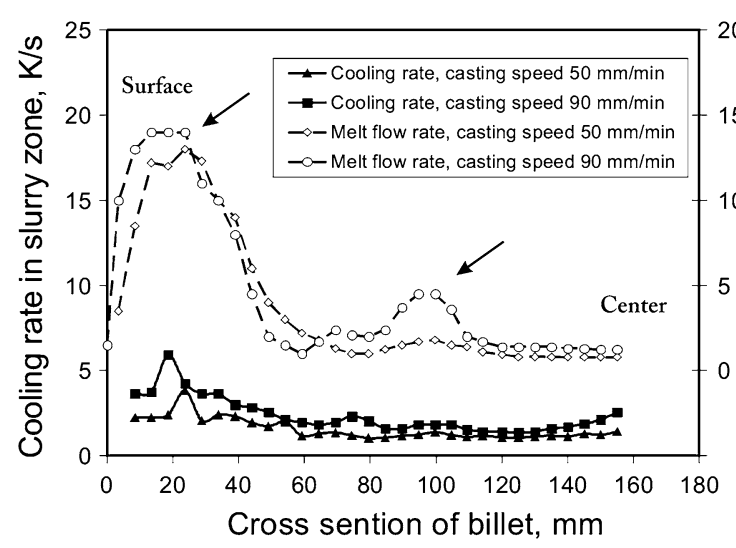

(a)
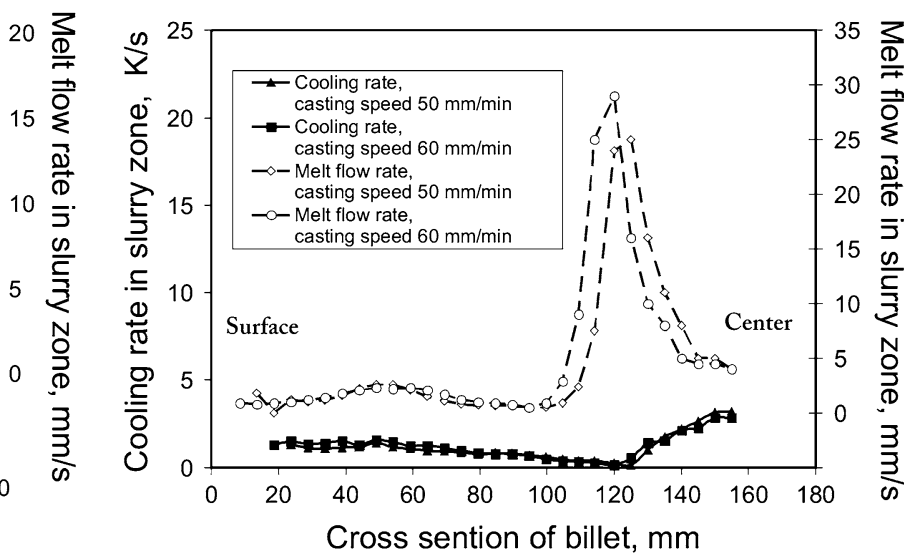

(b)

Fig. 11-Computer-simulated cooling rate in the transition region and the magnitude of the melt flow velocity in slurry zone: (a) semi-horizontal melt feeing scheme and $(b)$ vertical melt feeding scheme.

strongly depends on the amount of nucleation sites, which can be increased by multiplication of solidification sites by fragmentation through intense forced convection. So both cooling rate and fragmentation effect should be considered in the analysis of the grain size distribution. The transport of nucleating particles, e.g., $\mathrm{TiB}_{2}$, can be yet another factor in the degree of grain refinement influenced by the melt flow. It is well known that only small fraction of these particles is realized as nucleation substrates ${ }^{[25]}$ so we expect that the effect of the overall melt flow on their distribution will be subtle. This might be a subject of a separate study.

Figures 11(a) and (b) give combinations of cooling rate and flow velocity in the slurry zone. With these data, both fragmentation effect in the slurry zone (high velocity) and the cooling rate in the transition region are considered. The coherency temperature in this simulation is taken as $884 \mathrm{~K}\left(611^{\circ} \mathrm{C}\right)$ for AA7050 alloy. The solid fraction at coherency point is 0.5 , because all billets in this research are grain refining. ${ }^{[9]}$ The flow velocity in the slurry zone in Figure 11 is computer-simulated magnitude of melt flow velocity which is taken around the isotherm reflecting 0.4 fraction solid.

As illustrated in Figure 11, the grain size is clearly determined by a combination of movement/fragmentation effect and cooling rate. In Figure 11(a), two peaks of flow velocity in the slurry zone represent stronger fragmentation effect in these areas (around 20 and $100 \mathrm{~mm}$ away from the surface, as shown with arrows in Figure 11(a)). When we look back in Figure 2, we can find that due to this strong fragmentation effect, the grain size decreases near these areas, but with $20 \mathrm{~cm}$ shift along the flow direction (around 40 and $120 \mathrm{~mm}$ away from the surface). This can be explained by the movement and settling of substrates created by fragmentation along the flow in the slurry zone. Similarly, in vertical feeding billets, the grain size starts to decrease (from the position $100 \mathrm{~mm}$ away from the surface, as shown in Figure 6) when the fragmentation effect is getting stronger, as shown in Figure 11(b). The transport of fragments is weakened in this case due to the vertical solidification front. Although the flow velocity in the center is relative weak, the cooling rate in the center is quite high. This is why small grain size can still be obtained in the center (Figure 6).

The origins of coarse grains layer (Figure 8) may be affected by sump profile as well. As shown in Figure 9, a cliff-shaped sump leads to an almost vertical solidification front approximately $40 \mathrm{~mm}$ away from the center. The upstream flow and steep solidification front allow us to suggest that the grains, which are formed in the slurry zone around this vertical solidification front or formed earlier at other position and then transported to this area by melt flow, will stack and grow at the same position of almost vertical solidification front because of strong upstream melt flow that counteracts gravity. The low cooling and solidification rates in this region (Figure 10(b)) further promote the formation of these coarse grains.

\section{CONCLUSIONS}

The effect of melt feeding scheme and casting parameters on microstructure during DC casting were studied by both experiment and computer simulation. Experimental and simulation results clearly show that casting speed and melt feeding scheme are crucial factors affecting cast structures in DC casting of Al alloy billets. These factors mainly affect grain size through different sump profiles and flow patterns in the slurry region during solidification.

Increasing casting speed produces a deeper sump and a higher cooling rate in the solidification range, which results in refinement of grain structure. The distribution of cooling rate and final grain size in a cross section of the billet are dependent on melt feeding schemes. Upon semi-horizontal melt feeding, a relatively gentle slope of the solidification front towards to the center can be found. The fragmentation effect (flow velocity) in slurry zone is most intense near the surface. During vertical melt feeding, the sump profile is cliff-shaped. The slope of the sump suddenly increases at the position $40 \mathrm{~mm}$ away from the center. The flow velocity is most intense 
in the center. The combination of fragmentation effect in the slurry zone and cooling rate in the solidification range is the main factor affecting final grain structure and its distribution across the DC casting billet. As a result, grains tend to coarsen towards the center of a billet cast with the semi-horizontal melt feeding, while upon vertical melt feeding, the minimum grain size is observed in the center of the billet. The grain size usually decreases at the position where intense melt flow in the slurry zone is or the high cooling rate is. The geometry of the sump also can affect grain structure by restricting the movement of solid grains in the slurry zone. Coarse grains layer found near the center in the billet cast with the vertical feeding may be an example for this mechanism.

\section{ACKNOWLEDGMENTS}

This research was carried out under project number MA.10210 in the framework of the Research Program of the Materials innovation institute M2i (www.m2i.nl). The author would like to express their gratitude to Dr Démian Ruvalcaba and Mr Jacob van Oord (Tata Steel Research, Development \& Technology, The Netherlands) for their support and inputs. L. Zhang would like to thank China Scholarship Council and Prof. J.S. Zhang for providing the scholarship for the PhD study at TU Delft.

\section{REFERENCES}

1. B.S. Murty, S.A. Kori, and M. Chakraborty: Int. Mater. Rev., 2002, vol. 47, pp. 3-29.

2. J.R. Davis: ASM Specialty Handbook: Aluminum and Aluminum Alloys, ASM International, Handbook Committee, Materials Park, OH, 1993, p. 98.
3. R. Nadella, D.G. Eskin, and L. Katgerman: Metall. Mater. Trans. A, 2008, vol. 39A, pp. 450-61.

4. D.G. Eskin, V.I. Savran, and L. Katgerman: Metall. Mater. Trans. A, 2005, vol. 36A, pp. 1965-76.

5. D.G. Eskin, J. Zuidema, V.I. Savran, and L. Katgerman: Mater. Sci. Eng. A, 2004, vol. 384, pp. 232-44.

6. V.A. Livanov, R.M. Gabidullin, and V.S. Shepilov: DC Casting of Aluminium Alloys, Metallurgiya, Moscow, 1977, pp. 20-30.

7. R.C. Dorward and D.J. Beerntsen: Light Metals, TMS, Warrendale, PA, 1990, pp. 919-24.

8. D.G. Eskin: Physical Metallurgy of Direct Chill Casting of Aluminum Alloys, CRC Press, Boca Roton, 2008, p. 79.

9. L. Arnberg, L. Bäckerud, and G. Chai: in Solidification Characteristics of Aluminum Alloys, vol. 3: Dendrite Coherency, American Foundrymen's Society, Des Plaines, IL, 1996, pp. 227-232.

10. R. Nadella, D.G. Eskin, Q. Du, and L. Katgerman: Prog. Mater. Sci., 2008, vol. 53, pp. 421-80.

11. M.C. Flemings: Metall. Trans., 1974, vol. 5, pp. 1974-2121.

12. M.A. Easton and D.H. StJohn: Mater. Sci. Eng. A, 2008, vol. 486, pp. 8-13.

13. D.G. Eskin, Q. Du, D. Ruvalcaba, and L. Katgerman: Mater. Sci. Eng. A, 2005, vol. 405, pp. 1-10.

14. P.R. Beeley: Foundry Technology, Butterworth, London, 1972, pp. $40-78$

15. M. Založnik, A. Kumar, H. Combeau, M. Bedel, P. Jarry, and E. Waz: Light Metals, TMS, Warrendale, PA, 2011, pp. 699-704.

16. D.G. Eskin, A. Jafari, and L. Katgerman: Mater. Sci. Technol., 2011, vol. 27, pp. 890-96.

17. B. Gariepy and Y. Caron: Light Metals 1991, TMS, Warrendale, PA, 1990, pp. 961-71.

18. D. Mortensen: Metall. Mater. Trans. B, 1999, vol. 30B, pp. 119 33 .

19. D. Mortensen, H.G. Fjær, D. Lindholm, M. Rudshaug, and E.A. Sørheim: Mater. Sci. Forum, 2011, vol. 693, pp. 187-95.

20. M. Lalpoor, D.G. Eskin, D. Ruvalcaba, H.G. Fjær, A. TenCate, N. Ontijt, and L. Katgerman: Mater. Sci. Eng. A, 2011, vol. 528, pp. 2831-42.

21. E.F. Emley: Int. Met. Rev., 1976, vol. 206, pp. 75-115.

22. A. Hakonsen, M. Mortensen, S. Benum, and H.E. Vatne: Light Metals, TMS, Warrendale, PA, 1999, pp. 821-27.

23. W. Roth: Aluminium, 1943, vol. 25, pp. 283-91.

24. D.C. Prasso, J.W. Ewans, and I.J. Wilson: Metall. Mater. Trans. B, 1995, vol. 26B, pp. 1243-51.

25. A.L. Greer, P.S. Cooper, M.W. Meredith, W. Schneider P. Schumacher, J.A. Spittle, and A. Tronche: Adv. Eng. Mater., 2003, vol. 5 (1-2), pp. 81-91. 